\title{
Qualidade de sementes e mudas de Cedrela fissilis Vell. em função da biometria de frutos e sementes em diferentes procedências
}

Quality of seeds and seedlings of Cedrela fissilis Vell. due to the biometry of berry and seeds in different origins

\section{Mariane de Oliveira Pereira ${ }^{1}$, Marcio Carlos Navroski ${ }^{2 *}$, Pablo Melo Hoffmann ${ }^{1}$, Jeniffer Grabias ${ }^{1}$, Christopher Thomas Blum ${ }^{1}$, Antonio Carlos Nogueira ${ }^{1}$, Diego Pereira Rosa ${ }^{2}$}

Submissão: 05/03/2016 / Aceite: 17/04/2017

\section{RESUMO}

Cedrela fissilis é espécie nativa do Brasil com uso destacado no setor madeireiro e na recuperação de áreas degradadas, existindo a necessidade de melhor entendimento das diferenças e ganhos genéticos que pode haver em relação a diferentes procedências e progênies. O objetivo do estudo foi analisar a biometria de frutos e sementes de Cedrela fissilis em função de diferentes procedências e matrizes relacionando com o crescimento inicial de mudas, além de avaliar o melhor fotoperíodo na germinação. As sementes foram coletadas em matrizes de duas procedências (Fernandes Pinheiro e Lapa) para biometria e peso de mil sementes por matriz. Sementes das duas procedências foram submetidas a distintos fotoperíodos (12, 16 e 24 horas de luz branca e 24 horas no escuro), sendo avaliada a germinação e o Índice de Velocidade de Germinação (IVG). O crescimento inicial das mudas foi avaliado através da medição de características morfológicas a cada 30 dias após a repicagem das plântulas. Os experimentos foram realizados em delineamento inteiramente casualizado e os dados submetidos à análise de variância ao nível de 5\%, sendo as médias comparadas pelo teste de Tukey e/ou regressão polinomial. Houve diferença biométrica de frutos e sementes entre as matrizes, não havendo relação com a procedência. Quanto a taxa de germinação e IVG entre as procedências, Fernandes Pinheiro apresentou os melhores resultados. Em relação ao fotoperíodo, não existiu diferença na germinação em relação aos níveis de luz, sendo o IVG maior para sementes germinadas no escuro. A procedência Fernandes Pinheiro obteve maior crescimento inicial das mudas em relação à procedência Lapa e esta diferença aumenta ao longo das avaliações. Em geral, os experimentos mostraram haver diferença entre as procedências, havendo relação com a qualidade de sementes e mudas formadas.

PALAVRAS-CHAVE: cedro, fotoperíodo, matrizes, produção de mudas, Meliaceae.

\section{ABSTRACT}

Cedrela fissilis is a Brazilian native species with outstanding use in the timber sector and in the recovery of degraded areas. There is a need for a better understanding of the differences and genetic gains that may exist in relation to different origins and progenies. The objective of the study was to analyze the biometry of fruits and seeds of Cedrela fissilis as a function of different origins and matrices related to the initial growth of seedlings, besides evaluating the best photoperiod in germination. The seeds were collected in matrices from two sources (Fernandes Pinheiro and Lapa) for biometry and the weight of one thousand seeds per matrix. Seeds of the two provenances were submitted to different photoperiods (12, 16 and 24 hours of white light and 24 hours in the dark), the germination and the germination rate index (ORI) was evaluated. The initial growth of the seedlings was evaluated through the measurement of morphological characteristics after every 30 days. The experiments were performed in a completely randomized design and the data submitted to analysis of variance at the $5 \%$ level, the averages being compared by the Tukey test and/or polynomial regression. There were biometric differences between fruits and seeds between the matrices, with no relation to the origin. Regarding the germination rate and ORI among the

${ }^{1}$ Universidade Federal do Paraná, Curitiba, PR, Brasil.

${ }^{2}$ Universidade do Estado de Santa Catarina, Lages, SC, Brasil.

*Autor para correspondência <marcio.navroski@udesc.br> 
provenances, Fernandes Pinheiro presented the best results. In relation to the photoperiod, there was no difference in germination in relation to light levels, and the ORI was higher for seeds germinated in the dark. Fernandes Pinheiro obtained higher initial growth of the seedlings in relation to the Lapa origin and this difference increases throughout the evaluations. In general, the experiments showed a difference between the provenances, having a relation with the quality of seeds and seedlings formed.

KEYWORDS: cedro, photoperiod, seed-tree, seedling production, Meliaceae.

\section{INTRODUÇÃO}

Conhecida popularmente como cedro, cedrorosa ou cedro-branco, Cedrela fissilis Vellozo, pertence à família Meliaceae, tendo sua área de distribuição natural desde o Sul do Brasil $\left(32^{\circ} \mathrm{S}\right)$ até a Costa Rica, na América Central $\left(12^{\circ} \mathrm{N}\right)$ (CARVALHO 2003). Apresenta vasta e expressiva dispersão por praticamente todas as florestas dos estados do Paraná, Santa Catarina e Rio Grande do Sul (CARVALHO 2005). Foi classificada como ameaçada de extinção na lista vermelha de espécies ameaçadas da International Union for Conservation of Nature, sendo que no Brasil segundo a Lista Nacional Oficial de Espécies da Flora Ameaçadas de Extinção, a espécie encontrase na categoria vulnerável (MMA 2014).

É uma árvore caducifólia, apresentando de 10 a $25 \mathrm{~m}$ de altura e podendo atingir até 40 metros de altura e $300 \mathrm{~cm}$ de DAP na idade adulta, sendo considerada uma espécie secundária na sucessão ecológica. A floração ocorre de setembro a janeiro e os frutos amadurecem após a queda das folhas, entre julho e agosto no estado do Paraná, sendo que uma árvore isolada chega a produzir mais de 1.500 frutos, com mais de 60.000 sementes férteis (CARVALHO 2003).

A análise de sementes é uma atividade importante na atividade florestal fornecendo respostas que representem a qualidade física e fisiológica do lote de sementes para fins de semeadura e armazenamento ao longo do tempo (WIELEWICKI et al. 2006). Os tecnologistas de sementes florestais encontram dificuldades no estabelecimento de condições e técnicas adequadas para os diferentes tipos de sementes. Os problemas decorrem da diversidade morfológica dos frutos e da dificuldade de extração das sementes. As informações são escassas para a definição de procedimentos capazes de ampliar o período de conservação das sementes, já que o conhecimento atual é limitado e concentrado (MARTINS \& LAGO 2008), principalmente em espécies florestais.

O tamanho e as características das sementes são de grande importância para o estudo de uma espécie. É um parâmetro fundamental para conhecer a dispersão e o estabelecimento de plântulas. Durante a maturação, as sementes crescem em tamanho até atingirem o valor característico para a espécie, porém dentro da mesma espécie existem variações individuais, de ano para ano e inclusive dentro da mesma árvore (COSTA et al. 2006). Dentro de uma única espécie há variações na dimensão das sementes, justificado pelas influências ambientais durante o desenvolvimento das sementes e a variabilidade genética, podendo variar no tamanho das sementes entre e dentro de árvores matrizes (SANTOS et al. 2009).

Estudos envolvendo a análise morfológica de frutos e sementes podem auxiliar no entendimento do processo de germinação, vigor, armazenamento, viabilidade e métodos de propagação das espécies. Além disso, a caracterização morfológica de frutos e sementes fornece subsídios para diferenciar espécies e caracterizar aspectos ecológicos da planta, como a dispersão, estabelecimento de plântulas e fase da sucessão ecológica (MATHEUS \& LOPES 2007). Já a classificação das sementes por tamanho ou por peso é uma estratégia que pode ser adotada para uniformizar a emergência das plântulas e para a obtenção de mudas de tamanho semelhante ou de maior vigor (MACEDO et al. 2009).

Vários testes podem avaliar a qualidade de sementes, incluindo condutividade elétrica, teste de tetrazólio, germinação, crescimento de plântulas, envelhecimento acelerado, tamanho de plântulas, IVG, entre outros (MARCOS FILHO et al. 2009).

A utilização de sementes de baixa qualidade é um dos fatores responsáveis pela formação de mudas inadequadas de espécies florestais, gerando reflexos negativos no estabelecimento, no crescimento e na uniformidade dos povoamentos (MUNIZ et al. 2007). A qualidade das mudas pode ser definida tanto por características morfológicas, nutricionais e fisiológicas, resultantes tanto de fatores genéticos como de procedimento de manejo de viveiro. Essa qualidade das mudas tem sido avaliada por meio da sobrevivência e do desenvolvimento da muda no 
viveiro e no campo, e os resultados têm sido muito variáveis, mesmo com plantas consideradas de alto padrão de qualidade morfológica (FONSECA et al. 2006).

Dentre os resultados de qualidade de mudas, e de crescimento no campo, apresenta-se uma grande influência genética e ambiental, no qual a variação genética seria passível de seleção para características qualitativas ou quantitativas, principalmente nos trabalhos iniciais com espécies nativas como o cedrorosa, destacando-se testes de procedências e seleção de matrizes, para manutenção de variabilidade.

Com o cedro-rosa não são encontrados na literatura estudos de conservação, diversidade genética, seleção de genótipos superiores e, aspectos silviculturais com a mesma frequência que outras meliáceas de importância econômica. Portanto, acredita-se que pesquisas voltadas à seleção de matrizes e procedências com alta diversidade e elevada produtividade, aliado à silvicultura adequada podem contribuir para viabilizar a domesticação da espécie e utilização em escala comercial.

O presente trabalho teve por objetivo analisar a biometria de frutos e sementes de Cedrela fissilis em função de diferentes procedências e matrizes relacionando com o crescimento inicial de mudas, além de avaliar o melhor fotoperíodo na germinação.

\section{MATERIAL E MÉTODOS}

\section{Seleção, coleta e biometria de frutos e sementes}

Foram colhidos frutos de quatro matrizes de Cedrela fissilis da Reserva Particular do Patrimônio Natural (RPPN) Uru (matrizes LA29 e LAsn), no município da Lapa (2548'48"S; 4941'36”W) e da Fazenda Benfica (matrizes FP126 e FP42), remanescente florestal situado no município de Fernandes Pinheiro (25³2’35’S; 50²8’29’W), ambas na região fitogeográfica da Floresta com Araucária no estado do Paraná (RODERJAN et al. 2002).

Para o estado do Paraná, a classificação climática de Köppen indica um clima subtropical úmido tipo $\mathrm{Cfb}$ (temperado e úmido) para Fernandes Pinheiro e Lapa. Apresentam verões amenos, invernos com ocorrências de geadas severas e frequentes, não apresentando estação seca. Em Fernandes Pinheiro a temperatura média anual é de $17{ }^{\circ} \mathrm{C}$ a $18{ }^{\circ} \mathrm{C}$, precipitação anual entre $1600 \mathrm{~mm}$ a $1800 \mathrm{~mm}$ e umidade relativa do ar média entre 70 a $75 \%$. Já em
Lapa, a temperatura média anual é de $16^{\circ} \mathrm{C}$ a $17^{\circ} \mathrm{C}$, precipitação anual entre $1200 \mathrm{~mm}$ a $1400 \mathrm{~mm}$ e umidade relativa do ar média entre 80 a $85 \%$ (IAPAR 2014).

Para a escolha das matrizes respeitou-se uma distância mínima de 100 metros entre indivíduos, escolhendo-se aqueles do interior da floresta. Os frutos foram coletados no início do desenvolvimento da coloração castanha, ainda fechados, diretamente das matrizes (KUNIYOSHI 1983) no mês de julho de 2012. Após a coleta foram selecionados 30 frutos de cada procedência para a biometria, sendo realizadas medições de largura, comprimento, biomassa fresca e número de sementes por fruto. O material foi armazenado por aproximadamente 15 dias em local seco e arejado até que iniciassem a abertura espontânea e liberação das sementes. Foram utilizadas 120 sementes (60 de cada procedência) para medição da largura (eixo transversal médio) e do comprimento (comprimento total com ala). Na determinação das dimensões utilizou-se um paquímetro digital com precisão de $0,01 \mathrm{~mm}$.

\section{Fotoperíodo e matrizes na análise da qualidade fisiológica}

Para a obtenção do peso de mil sementes foram utilizadas oito repetições de 100 sementes por procedência. $\mathrm{O}$ grau de umidade foi obtido com três repetições de $5 \mathrm{~g}$ a $105^{\circ} \mathrm{C}$ por 24 horas em estufa. Os testes de umidade e peso de mil sementes foram realizados de acordo com as Regras de Análise de Sementes (RAS) (BRASIL 2009).

O experimento de germinação condicionado a distintos fotoperíodos foi executado em delineamento inteiramente casualizado com arranjo fatorial $4 \times 2$, sendo os níveis do fator A constituídos por quatro diferentes períodos de luz (12, 16 e 24 horas de luz; 24 horas de escuro), e os níveis do fator D constituídos de duas procedências (Fernandes Pinheiro e Lapa), com quatro repetições de 30 sementes por unidade experimental.

O teste foi realizado em gerbox transparentes para os tratamentos com luz branca e gerbox pretos para os tratamentos no escuro. As sementes foram colocadas sobre duas folhas de papel tipo mata-borrão umedecidas com água destilada, na quantidade de 2,5 vezes a massa do substrato seco (BRASIL 2009). O teste de germinação foi conduzido sob temperatura de $25{ }^{\circ} \mathrm{C} \pm 2{ }^{\circ} \mathrm{C}$ em câmara de germinação do tipo Biochemical Oxygen Demand (B.O.D.) no 
Laboratório de Análise de Sementes Florestais da Universidade Federal do Paraná. Durante a condução do experimento foi avaliado o índice de velocidade de germinação (IVG), sendo contabilizadas as sementes germinadas a cada dois dias, a partir da protrusão da radícula com no mínimo $1 \mathrm{~cm}$ de comprimento até o dia da última contagem, a qual foi encerrada aos 40 dias após a instalação do experimento. O IVG foi calculado de acordo com MAGUIRE (1962). Quando a germinação estabilizou, o experimento foi encerrado e então foi avaliada a porcentagem de germinação.

\section{Crescimento inicial de mudas}

Para a avaliação do crescimento inicial das mudas e do desenvolvimento em viveiro foram semeadas 400 sementes de cada procedência em bandejas plásticas $(40$ x $50 \mathrm{~cm})$ no Viveiro de Espécies Nativas da Sociedade Chauá, sendo mantidas em estufa plástica com irrigação diária de $5 \mathrm{~mm}$ de lâmina. Após 60 dias foram transferidas 200 plântulas de cada procedência para tubetes de 110 $\mathrm{cm}^{3}$ com substrato comercial Mecplant ${ }^{\circledR}$, distribuídas em dez repetições de 20 plântulas cada. No momento da repicagem foram avaliados a altura da parte aérea (do colo até o meristema apical) e diâmetro do colo. As medidas foram obtidas com régua e paquímetro digital com precisão de $0,01 \mathrm{~mm}$.

A partir da data de repicagem foram avaliados a altura da parte aérea e o diâmetro do colo das mudas aos 60, 90 e 120 dias. Aos 60 dias também foi avaliada a permanência de cotilédones em cada muda por meio da visualização da presença ou ausência dos mesmos. Na última avaliação uma amostra de cinco mudas de cada repetição foi avaliada quanto a biomassa fresca de raiz (BFR), biomassa fresca da parte aérea (BFPA), biomassa seca de raiz (BSR), biomassa seca da parte aérea (BSPA), altura da parte aérea e diâmetro do colo (DC). Para as variáveis de biomassa foi utilizada balança de precisão de $0,01 \mathrm{~g}$. As amostras foram colocadas em estufa com temperatura de $60^{\circ} \mathrm{C}$ por 48 horas e, após este período, foram novamente pesadas para determinação das biomassas secas.

\section{Análise estatística dos dados}

Após avaliar a normalidade pelo teste de Kolmogorov-Smirnov e a homogeneidade de variâncias, por meio do teste de Bartlett, os dados de todos os experimentos foram submetidos à análise de variância(ANOVA) ao nível de significância de $\alpha=0,05$. Quando necessário, realizou-se o desdobramento das interações, sendo as médias comparadas pelo teste de Tukey e/ou regressão polinomial a 5\% de probabilidade de erro. Considerou-se como fator quantitativo o tempo (na interação procedência $\mathrm{x}$ tempo de avaliação) para melhor visualização dos dados de crescimento. O programa estatístico Sisvar foi utilizado para a análise estatística dos dados.

\section{RESULTADOS E DISCUSSÃO}

\section{Biometria de frutos e sementes}

Houve diferença estatística $(p \leq 0,05)$ entre as matrizes, para todas as variáveis biométricas avaliadas: largura, comprimento e biomassa fresca de frutos, número de sementes por fruto, largura e comprimento das sementes (Tabela 1), podendo-se inferir que essas diferenças se devem, principalmente, a efeitos genéticos e/ou microambientais, visto que as matrizes estão localizadas em áreas aparentemente com pouca variação macroambiental como, por exemplo, de temperatura e precipitação.

Quanto à largura dos frutos as matrizes FP126 e FP42 não diferiram da matriz LA29 (Tabela 1). A matriz LAsn apresentou a menor largura dos frutos, distinguindo-se das demais. O comprimento dos frutos foi maior na matriz LA29 $(7,6 \mathrm{~cm})$ e se diferenciaram estatisticamente de todas as outras matrizes. Quanto a biomassa fresca dos frutos igualmente a matriz LA29 apresentou maior média ( $15 \mathrm{~g})$ enquanto que a matriz FP42 apontou a menor $(10,4 \mathrm{~g})$ em comparação às demais. $\mathrm{O}$ maior número de sementes por fruto foi obtido pelas matrizes LA29, FP126 e LAsn, diferentemente da matriz FP42 que obteve o menor número. CORVELLO et al. (1999) encontraram em média 32 sementes por fruto de cedro, sendo que para as matrizes do presente estudo esse valor variou de 28 a 36.

Conforme MACEDO et al. (2009) o número de sementes produzido por fruto pode ser diretamente influenciado pelas condições ambientais, mais especificamente pelas variações microambientais, como observado no presente trabalho. Além disso, os mesmos autores comentam que em alguns casos a disponibilidade hídrica durante o florescimento representa um fator relevante na produtividade, afetando no número de sementes e ligeiramente no tamanho das mesmas. No entanto, no caso do respectivo trabalho não foram coletados dados meteorológicos para serem correlacionados com os dados biométricos. 
Tabela 1. Resumo da análise de variância e comparação das médias para largura de frutos (LF), comprimento de frutos (CF), número de sementes por fruto, peso de frutos (PF), largura de sementes (LS) e comprimento de sementes (CS) de Cedrela fissilis provenientes de diferentes matrizes.

Table 1. Summary of analysis of variance and comparison of means for fruit width (LF), length of fruits (CF), number of seeds per fruit, fruit weight (PF), seed width (LS) and length of (CS) Cedrela fissilis seeds from various seed-trees

\begin{tabular}{|c|c|c|c|c|c|c|}
\hline \multirow{2}{*}{$\begin{array}{l}\text { Fonte de } \\
\text { variação }\end{array}$} & \multicolumn{4}{|c|}{ Biometria frutos } & \multicolumn{2}{|c|}{ Biometria sementes } \\
\hline & $\mathrm{LF}(\mathrm{cm})$ & $\mathrm{CF}(\mathrm{cm})$ & Sem./Fruto & $\mathrm{BFF}(\mathrm{g})$ & $\mathrm{LS}(\mathrm{mm})$ & $\mathrm{CS}(\mathrm{mm})$ \\
\hline Matriz & $0,1936^{* *}$ & $3,3523^{* *}$ & $83,3764^{* *}$ & $42,0212^{* *}$ & $84,2444^{* *}$ & $35,9333^{* *}$ \\
\hline Erro & 0,019 & 10,1845 & 27,4376 & 2,7334 & 1,2390 & 4,0079 \\
\hline Média & 3,00 & 6,77 & 35,43 & 12,55 & 10,63 & 26,66 \\
\hline CV $(\%)$ & 4,63 & 3,34 & 14,90 & 13,17 & 10,45 & 7,80 \\
\hline Matriz & & & & Médias & & \\
\hline LA29 & $3,1 \mathrm{a}^{*}$ & $7,6 \mathrm{a}$ & $36,3 \mathrm{a}$ & $15,0 \mathrm{a}$ & $12,1 \mathrm{a}$ & $27,2 \mathrm{a}$ \\
\hline FP126 & $3,0 \mathrm{a}$ & $6,5 \mathrm{~b}$ & $36,2 \mathrm{a}$ & $12,8 \mathrm{~b}$ & $9,1 \mathrm{~b}$ & $25,1 \mathrm{~b}$ \\
\hline FP42 & $2,9 \mathrm{ab}$ & $6,8 \mathrm{~b}$ & $28,8 \mathrm{~b}$ & $10,4 \mathrm{c}$ & $12,0 \mathrm{a}$ & $24,7 \mathrm{~b}$ \\
\hline LAsn & $2,8 \mathrm{~b}$ & $6,5 \mathrm{~b}$ & $35,3 \mathrm{a}$ & $11,1 \mathrm{bc}$ & $9,2 \mathrm{~b}$ & $25,1 \mathrm{~b}$ \\
\hline Máximo & 3,3 & 8,5 & 48,0 & 19,8 & 14,0 & 32,0 \\
\hline Mínimo & 2,5 & 5,6 & 24,0 & 8,5 & 7,0 & 21,0 \\
\hline
\end{tabular}

As sementes das matrizes LA29 e FP42 apresentaram maior largura (12,1 e 12,0 mm, respectivamente). Já em relação ao comprimento das sementes, a matriz LA29 obteve o maior valor $(27,2 \mathrm{~mm})$ diferindo das demais matrizes (Tabela 1).

O conhecimento da variação biométrica de caracteres de frutos e sementes é importante para o melhoramento dessas características, seja no sentido de aumento ou uniformidade (GONÇALVES et al. 2013). Desta forma, a distinção e classificação das sementes por tamanho pode ser uma maneira eficiente de melhorar a qualidade de lotes de sementes em relação à uniformidade de emergência e vigor das plântulas (PEDRON et al. 2004), principalmente em relação ao diâmetro do colo, a biomassa aérea e radicular e a altura da parte aérea. Desse modo, a seleção e a classificação das sementes é uma técnica que deve ser levada em consideração para a produção de mudas mais vigorosas e uniformes (PEREIRA et al. 2008).

Essa variação de tamanho de frutos e sementes dentro da mesma espécie pode ser explicada pelas variações individuais, influência de fatores bióticos e abióticos durante o desenvolvimento das sementes e à variabilidade genética. Assim, o tamanho e a massa de sementes podem variar entre plantas da mesma espécie, em diferentes períodos de coleta, também, dentro de uma mesma planta (SANTOS et al. 2009). Associada a esses e a outros fatores, a alteração da coloração dos frutos é uma característica que pode estar relacionada com a biometria dos frutos e das sementes devido ao ponto de maturidade fisiológica dos mesmos (CORVELLO et al. 1999). A variação entre indivíduos, numa mesma população, possibilita a seleção com vistas à melhoria de um dado caractere, constituindo-se numa das mais importantes fontes de variabilidade disponível para os melhoristas de plantas. 


\section{Fotoperíodo e matrizes na análise da qualidade fisiológica}

O peso de mil sementes encontrado após a coleta para o lote de sementes da procedência Lapa foi de $25,48 \mathrm{~g}$ e o grau de umidade correspondente foi de $23,9 \%$. Para a procedência Fernandes Pinheiro o peso de mil sementes foi de $36,10 \mathrm{~g}$ e grau de umidade de $17,6 \%$.

No que diz respeito ao peso de mil sementes de Cedrela fissilis, FORTES (2004) encontrou 20,65 g, como valor mínimo e 39,95 g como valor máximo para lotes de diferentes procedências. Com relação ao grau de umidade, o mesmo autor relatou que os valores para o grau de umidade mínimo e máximo encontrados para os diversos lotes foram de 6,7 e $13,6 \%$, respectivamente. Dessa forma, os valores encontrados neste estudo para peso de mil sementes estão dentro da faixa de valores descritos, já para o teor de umidade os valores obtidos são superiores.

No entanto, CORVELLO et al. (1999) constataram grau de umidade mais elevado, de $22,4 \%$, para sementes de Cedrela fissilis quando obtidas de frutos em início de deiscência com coloração marrom escura. A partir desse resultado, os autores comentam que a melhor fase para a coleta de sementes de alta qualidade da espécie, é quando se observa um menor grau de umidade nas sementes juntamente com uma elevada porcentagem de germinação e alto vigor. Com base nisso pode-se afirmar que os resultados do presente estudo corroboram com as orientações desses autores e estão próximos aos encontrados pelos mesmos.

Em relação a porcentagem de germinação e índice de velocidade de germinação (IVG) não houve interação $(p>0,05)$ entre as procedências e o fotoperíodo. Houve diferença significativa $(p \leq 0,01)$ para os fatores isolados, sendo que para procedências, a germinação e o IVG foram influenciados por este fator, já para a fotoperíodo houve diferenças significativa somente para IVG (Tabela 2).

A germinação e a velocidade de germinação de sementes de Cedrela fissilis foram influenciadas pela procedência de coleta das sementes. A procedência Fernandes Pinheiro obteve a maior germinação (96\%) diferenciando-se da procedência Lapa $(82,7 \%)$. $O$ índice de velocidade de germinação (IVG) também foi maior na procedência Fernandes Pinheiro $(3,55)$, superando a procedência Lapa $(3,00)$ (Tabela 2$)$.

A procedência das sementes parece desempenhar influência sobre a germinação e emergência de plântulas. Além da temperatura, outros fatores como clima e composição de solo seriam importantes na determinação do desempenho das sementes bem como da sua qualidade (CARVALHO \& NAKAGAWA 2000). No entanto, os maiores valores biométricos para frutos e sementes encontrados no presente estudo não corresponderam aos maiores valores de germinação e IVG. Causas genéticas (não controladas no presente estudo) provavelmente têm influência sobre esse resultado, sendo essas variações resultado de interações entre influências ambientais durante o desenvolvimento das sementes e à variabilidade genética da espécie, em especial às matrizes utilizadas no estudo.

Quanto ao fotoperíodo não foram observadas diferenças significativas na germinação. A luminosidade influenciou de forma significativa o IVG, sendo que o maior índice foi observado no regime de 24 horas no escuro. A menor velocidade de germinação foi obtida no maior fotoperíodo com luz (12 horas) (Tabela 2).

A ativação das sementes pela luz está ligada a um sistema de pigmento denominado fitocromo, e a sensibilidade à luz é dependente dos níveis endógenos de giberelina (GA) e ácido abscísico (ABA), bem como, a capacidade de resposta de giberelinas (SEO et al. 2009). Essa sensibilidade das sementes à luz é bastante variável de acordo com a espécie e a classe sucessional em que ela pertence, havendo influência positiva ou negativa na germinação. Espécies secundárias (como o cedro) ou clímax não têm especificidade sobre a necessidade de luz. Os resultados obtidos neste trabalho quanto à germinação mostram que as sementes de cedro germinam em elevada porcentagem $(>80 \%)$ em todas as condições testadas. Isso releva que, em condições naturais, as sementes possuem capacidade para germinar em diferentes condições de sombreamento, ou seja, as sementes de cedro são capazes de germinar bem sob o dossel e em condições de clareiras.

Corroborando com os resultados obtidos nesse estudo, FIGLIOLIA et al. (2006) não identificaram diferença na porcentagem de germinação na ausência de luz ou luz constante na cor clara e vermelha em sementes de Cedrela fissilis. Em Cedrela odorata também não foi constatada diferença na germinação sob diferentes regimes de luz aplicados (PASSOS et al. 2008). 
Tabela 2. Resumo da análise de variância e comparação das médias para porcentagem de germinação (\%) e índice de velocidade de germinação (IVG) de sementes de Cedrela fissilis coletadas de duas diferentes procedências e submetidas a diferentes fotoperíodos durante a germinação.

Table 2. Summary of analysis of variance and comparison of means for germination percentage (\%) and Speed Germinability (IVG) of Cedrela fissilis seeds collected from two different provenances and under different photoperiods during germination.

\begin{tabular}{|c|c|c|c|c|c|c|}
\hline \multirow{2}{*}{$\begin{array}{l}\text { Fonte de } \\
\text { variação }\end{array}$} & \multicolumn{4}{|c|}{ Biometria frutos } & \multicolumn{2}{|c|}{ Biometria sementes } \\
\hline & $\mathrm{LF}(\mathrm{cm})$ & $\mathrm{CF}(\mathrm{cm})$ & Sem./Fruto & $\mathrm{BFF}(\mathrm{g})$ & $\mathrm{LS}(\mathrm{mm})$ & $\mathrm{CS}(\mathrm{mm})$ \\
\hline Matriz & $0,1936^{* *}$ & $3,3523^{* *}$ & $83,3764^{* *}$ & $42,0212^{* *}$ & $84,2444^{* *}$ & $35,9333^{* *}$ \\
\hline Erro & 0,019 & 10,1845 & 27,4376 & 2,7334 & 1,2390 & 4,0079 \\
\hline Média & 3,00 & 6,77 & 35,43 & 12,55 & 10,63 & 26,66 \\
\hline $\mathrm{CV}(\%)$ & 4,63 & 3,34 & 14,90 & 13,17 & 10,45 & 7,80 \\
\hline Matriz & & & & Médias & & \\
\hline LA29 & $3,1 \mathrm{a}^{*}$ & $7,6 \mathrm{a}$ & $36,3 \mathrm{a}$ & $15,0 \mathrm{a}$ & $12,1 \mathrm{a}$ & $27,2 \mathrm{a}$ \\
\hline FP126 & $3,0 \mathrm{a}$ & $6,5 \mathrm{~b}$ & $36,2 \mathrm{a}$ & $12,8 \mathrm{~b}$ & $9,1 \mathrm{~b}$ & $25,1 \mathrm{~b}$ \\
\hline FP42 & $2,9 a b$ & $6,8 \mathrm{~b}$ & $28,8 \mathrm{~b}$ & $10,4 \mathrm{c}$ & $12,0 \mathrm{a}$ & $24,7 \mathrm{~b}$ \\
\hline LAsn & $2,8 \mathrm{~b}$ & $6,5 \mathrm{~b}$ & $35,3 \mathrm{a}$ & $11,1 \mathrm{bc}$ & $9,2 \mathrm{~b}$ & $25,1 \mathrm{~b}$ \\
\hline Máximo & 3,3 & 8,5 & 48,0 & 19,8 & 14,0 & 32,0 \\
\hline Mínimo & 2,5 & 5,6 & 24,0 & 8,5 & 7,0 & 21,0 \\
\hline
\end{tabular}

\section{Crescimento inicial de mudas}

Houve diferenças estatísticas $(\mathrm{p} \leq 0,01)$ entre as procedências, para todas as variáveis avaliadas: permanência de cotilédones, biomassa fresca de raiz, biomassa fresca da parte aérea, biomassa seca de raiz, biomassa seca da parte aérea, altura e diâmetro do colo (Tabela 3). A procedência Lapa obteve maior média em comparação à procedência Fernandes Pinheiro somente na variável permanência de cotilédones. Para as demais variáveis a procedência Fernandes Pinheiro obteve maiores médias, diferenciandose da procedência Lapa. Os resultados de maiores valores de biomassas foram refletidos pela maior porcentagem de germinação e de IVG obtidos para a procedência Fernandes Pinheiro, indicando mudas de melhor qualidade.

A procedência Lapa teve praticamente todas as mudas com permanência de cotilédones, até o $60^{\circ}$ dia, juntamente com o início da emergência das primeiras folhas. Durante o processo germinativo, as plântulas de Cedrela fissilis apresentam cotilédones de coloração verde e textura foliácea, expostos do tegumento da semente, os quais estão acima do nível do substrato, caracterizando a plântula como fanerocotiledonar e epígea (OLIVEIRA 1993). O cedro apresenta cotilédones frequentemente típicos de espécies pioneiras e secundárias iniciais, que logo no início do desenvolvimento da plântula assumem rapidamente a função de nutrição da mesma por meio de seus cotilédones fotossintetizantes (RESSEL et al. 2004), o que influencia diretamente na qualidade das mudas.

Estudos de análise morfológica de Cedrela fissilis aos 48 dias de plantio constataram que ainda havia a presença de cotilédones oblongos. Apresentando ainda eófilos compostos, trifoliados, 
Tabela 3. Resumo da análise de variância e porcentagem de mudas com permanência de cotilédones (após 60 dias de emergência), biomassa fresca de raiz (BFR), biomassa fresca da parte aérea (BFPA), biomassa seca de raiz (BSR), biomassa seca da parte aérea (BSPA), altura da parte aérea (altura) e diâmetro do colo(DC) de mudas de Cedrela fissilis em função de duas procedências aos 120 dias após repicagem.

Table 3. Summary of analysis of variance and percentage of seedlings with cotyledons stay (60 days after emergence), root fresh biomass (BFR), fresh biomass of shoot BFPA), root dry biomass (BSR), biomass shoot dry weight (BSPA), height and stem diameter (DC) of Cedrela fissilis seedlings due to two provenances at 120 days after transplanting.

\begin{tabular}{lccccccc}
\hline \multirow{2}{*}{ FV } & \multicolumn{7}{c}{ Quadrado médio } \\
\cline { 2 - 8 } & $\begin{array}{c}\text { Cotilédones } \\
(\%)\end{array}$ & BFR $(\mathrm{g})$ & $\begin{array}{c}\text { BFPA } \\
(\mathrm{g})\end{array}$ & $\begin{array}{c}\text { BSR } \\
(\mathrm{g})\end{array}$ & $\begin{array}{c}\text { BSPA } \\
(\mathrm{g})\end{array}$ & $\begin{array}{c}\text { Altura } \\
(\mathrm{cm})\end{array}$ & $\begin{array}{c}\text { DC } \\
(\mathrm{mm})\end{array}$ \\
\hline Procedência (P) & $0,7225^{* *}$ & $19,669^{* *}$ & $169,52^{* *}$ & $0,883^{* *}$ & $9,501^{* *}$ & $3.894,3^{* *}$ & $89,7^{* *}$ \\
Erro & 0,0436 & 3,117 & 4,811 & 0,1389 & 6,791 & 28,05 & 1,40 \\
\hline Média geral & 95,25 & 4,74 & 5,41 & 0,80 & 1,61 & 23,5 & 5,9 \\
CV\% & 21,94 & 37,22 & 40,49 & 40,30 & 14,99 & 21,6 & 18,3 \\
\hline Procedência & \multicolumn{7}{c}{ Médias } \\
\hline Lapa & $99,5 \mathrm{a}^{*}$ & $4,30 \mathrm{~b}$ & $4,11 \mathrm{~b}$ & $0,7112 \mathrm{~b}$ & $1,301 \mathrm{~b}$ & $19,9 \mathrm{~b}$ & $5,4 \mathrm{~b}$ \\
Fer. Pinheiro & $91,0 \mathrm{~b}$ & $5,18 \mathrm{a}$ & $6,72 \mathrm{a}$ & $0,8892 \mathrm{a}$ & $1,924 \mathrm{a}$ & $27,5 \mathrm{a}$ & $6,4 \mathrm{a}$ \\
\hline
\end{tabular}

*Letras minúsculas idênticas na vertical não diferem entre si a $5 \%$ de probabilidade de erro pelo teste Tukey.

**Significativo $(\mathrm{p} \leq 0,05)$ pelo teste $\mathrm{F}$.

de tamanhos desiguais, ápice agudo, base cuneada a obtusa, borda íntegra nos folíolos inferiores e o maior com borda crenulada, e ainda com os cotilédones oblongos, ápice e base obtusos (LOPES et al. 2012).

O sistema radicular, que obteve maiores biomassas fresca $(5,18 \mathrm{~g})$ e seca $(0,8892 \mathrm{~g})$ para a procedência Fernandes Pinheiro (Tabela 3), é o melhor e mais usado parâmetro nas pesquisas para determinar o crescimento das raízes. Estas variáveis são boas indicadoras da qualidade das mudas e desenvolvimento depois de plantadas no campo (ELOY et al. 2013).

A parte aérea e o diâmetro do colo na avaliação final (120 dias), também apresentaram maiores valores para a procedência Fernandes Pinheiro (Tabela 3) assim como ocorreu para as variáveis discutidas anteriormente de germinação, IVG e biomassas. Para melhor visualização do crescimento das mudas, procedeu-se a análise em esquema fatorial entre procedências $\mathrm{x}$ tempo de avaliação, sendo observado efeito significativo $(p<0,05)$ para a interação (Figura $1)$.

A procedência Fernandes Pinheiro apresentou as maiores médias de altura nas três avaliações efetuadas (Figura 1A). Essa diferença em altura aumentou com o passar do tempo, sendo que na avaliação aos 120 dias obteve-se 7,6 cm a mais para as mudas de Fernandes Pinheiro. Esses resultados de diferença no crescimento inicial de mudas de
Cedrela fissilis obtidas de diferentes procedências é corroborado no trabalho de NAVROSKI et al. (2016).

Apesar da altura da parte aérea ser uma variável muito importante e muito utilizada como parâmetro para expressar a qualidade de mudas, não se deve avaliar isoladamente, pois a altura proporciona apenas uma aproximação da capacidade fotossintética e área transpiratória, ignorando a arquitetura do caule e sistema radicular (RITCHIE et al. 2010).

$\mathrm{O}$ diâmetro de colo também foi maior na procedência Fernandes Pinheiro em comparação a procedência Lapa (Figura 1B). A diferença entre as duas procedências também aumentou com o tempo de avaliação. O maior acréscimo em diâmetro ocorreu no período entre 90 e 120 dias.

Diversos estudos (GOMES et al. 2002, GOMES \& PAIVA 2004) têm apontado que o diâmetro do colo é a variável que melhor prediz o desempenho no pósplantio, indicando a qualidade das mudas, porém ocorrem variações para cada espécie e condições de plantio (RITCHIE et al. 2010). O diâmetro do colo é, dentre as variáveis de mais fácil mensuração, a mais promissora para indicar a qualidade das mudas e possui estreita correlação não somente com a sobrevivência, mas, sobretudo, com o ritmo de crescimento das mudas após o plantio (BINOTTO et al. 2010).

A obtenção de mudas de qualidade é o final da primeira etapa, no qual a seleção de materiais superiores é útil para o plantio a campo, sendo que 

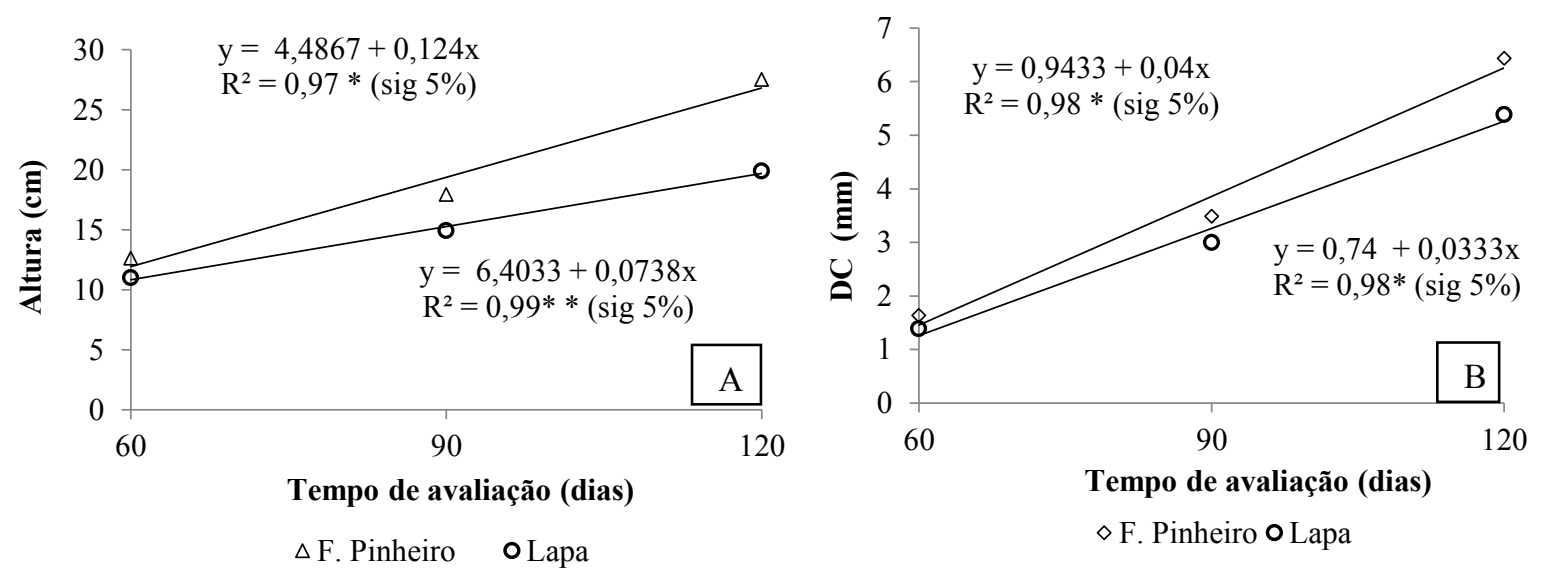

Figura 1. Altura (A) e diâmetro do colo (DC) (B) de mudas de Cedrela fissilis obtidas de sementes coletadas de duas procedências e diferentes tempos de avaliação.

Figure 1. Height (A) and stem diameter (DC) (B) of Cedrela fissilis seedlings obtained from seeds collected from two different times and different assessment.

esses resultados vão ser refletidos posteriormente na sobrevivência pós plantio, e dados qualitativos e quantitativos da floresta. É importante ter material superior, entretanto, deve-se sempre buscar a manutenção da variabilidade genética, principalmente em espécies como o cedro que apresenta problemas de pragas, e no qual, a conservação da variabilidade é indispensável.

\section{CONCLUSÕES}

As matrizes apresentam diferenças entre si, podendo-se recomendá-las quanto às maiores dimensões de frutos e sementes, as quais produzirão mudas de melhor qualidade.

Há diferença na germinação e IVG entre as procedências, com melhores resultados para Fernandes Pinheiro. Em relação ao fotoperíodo, não há diferença na germinação em relação aos níveis de luz, sendo o IVG maior para sementes germinadas no escuro.

A procedência Fernandes Pinheiro obteve maior crescimento inicial das mudas em relação à procedência Lapa e esta diferença aumenta ao longo das avaliações.

Em geral, a procedência Fernandes Pinheiro apresentou maior qualidade na germinação das sementes e maior crescimento inicial das mudas. Contudo, estudos mais longos devem ser conduzidos para expressar melhor a variação genética obtida em diferentes procedências.

\section{AGRADECIMENTOS}

A Sociedade Chauá, pela coleta e disponibilização das sementes e pelo espaço para a realização da pesquisa.

\section{REFERÊNCIAS}

BINOTTO AF et al. 2010. Correlations between growth variables and the Dickson quality index in forest seedlings. Cerne 16: 457-464.

BRASIL. 2009. Ministério da Agricultura, Pecuária e Abastecimento. Regras para análise de sementes. Brasília: Mapa/ACS. 399p.

CARVALHO PER. 2005. Cedro. Colombo: Embrapa Florestas. 17p. (Circular Técnica, 113).

CARVALHO PER. 2003. Espécies arbóreas brasileiras. Colombo: Embrapa Florestas. 1039p.

CARVALHO NM \& NAKAGAWA J. 2000. Sementes: ciência, tecnologia e produção. 4.ed. Jaboticabal: FUNEP. 588p.

CORVELLO WBV et al. 1999. Maturação fisiológica de sementes de cedro (Cedrela fissilis Vell.). Revista Brasileira de Sementes 21: 23-27.

COSTA RS et al. 2006. Aspectos morfológicos e influência do tamanho da semente na germinação do jambo-vermelho. Revista Brasileira de Fruticultura 28: 117-120.

ELOY E et al. 2013. Avaliação da qualidade de mudas de Eucalyptus grandis utilizando parâmetros morfológicos. Revista Floresta 43: 373-384.

FIGLIOLIA MB et al. 2006. Germinação de sementes de Lafoensia glyptocarpa Koehne (mirindiba-rosa), Myroxylon peruiferum L. f. (cabreúva-vermelha) e Cedrela fissilis Vell. (cedro-rosa). Revista Instituto Florestal 18: 4958.

FONSECA CA et al. 2006. Efeito da adubação nitrogenada na produção de mudas de sete-cascas (Samanea inopinata 
(Harms) Ducke). Revista Árvore 30: 537-546.

FORTES FO. 2004. Diagnóstico das análises de sementes de espécies florestais nativas e exóticas do estado do Rio Grande do Sul. Dissertação (Mestrado em Engenharia Florestal) Santa Maria: UFSM. 131p.

GOMES JM \& PAIVA HN. 2004. Viveiros florestais: propagação sexuada. 3.ed. Viçosa: UFV. 116p.

GOMES JM et al. 2002. Parâmetros morfológicos na avaliação da qualidade de mudas de Eucalyptus grandis. Revista Árvore 26: 655-664.

GONÇALVES LGV et al. 2013. Biometria de frutos e sementes de mangaba (Hancornia speciosa Gomes) em vegetação natural na região leste de Mato Grosso, Brasil. Revista de Ciências Agrárias, 36: 31-40.

IAPAR - Instituto Agronômico do Paraná. Agrometeorologia. 2014. Redes de Estações Meteorológicas do Paraná. Estações Meteorológicas Convencionais. Disponível em: http://www.iapar.br/modules/conteudo/ conteudo.php? conteudo=890: Acesso em: 29 nov. 2015 . KUNIYOSHI YS. 1983. Morfologia da semente e da germinação de 25 espécies arbóreas de uma floresta com araucária. Dissertação (Mestrado em Ciências Florestais) Curitiba: UFPR. 233p.

LOPES A et al. 2012. Caracterização morfológica das plântulas de cinco espécies arbóreas da floresta estacional semidecidual, Brasil. Revista Floresta, 42: 105-114.

MACEDO MC et al. 2009. Biometria de frutos e sementes e germinação de Magonia pubescens ST. Hil (Sapindaceae). Revista Brasileira de Sementes 31: 202-211.

MAGUIRE JD. 1962. Speed of germination-aid selection and evaluation for seedling emergence and vigor. Crop Science 2: 176-177.

MMA - Ministério do Meio Ambiente. 2014. Lista Nacional Oficial de Espécies da Fauna Ameaçadas de Extinção. Portaria $\mathrm{n}^{\circ} 444$ de 17 de dezembro de 2014 - Anexo I. Diário Oficial da União - Seção 1, 18/12/2014.

MARCOS FILHO J et al. 2009. Métodos para avaliação do vigor de sementes de soja, incluindo a análise computadorizada de imagens. Revista Brasileira de Sementes 31: 102-112.

MARTINS L \& LAGO AA. 2008. Conservação de semente de Cedrela fissilis: teor de água da semente e temperatura do ambiente. Revista Brasileira de Sementes 30: 161-167. MATHEUS MT \& LOPES JC. 2007. Morfologia de frutos, sementes e plântulas e germinação de sementes de Erythrina variegata L. Revista Brasileira de Sementes 29: 8-17.

MUNIZ MFB et al. 2007. Influência da assepsia e do substrato na qualidade de sementes e mudas de espécies florestais. Revista Brasileira de Sementes 29: 140-146.

NAVROSKI MC et al. 2016. Procedência e adubação no crescimento inicial de mudas de cedro. Pesquisa Florestal Brasileira 85: 17-24.

OLIVEIRA EC. 1993. Morfologia de plântulas. In: AGUIAR IB et al. Sementes florestais tropicais. Brasília:
ABRATES. p.175-214.

PASSOS MAA et al. 2008. Luz, substrato e temperatura na germinação de sementes de cedro-vermelho. Pesquisa Agropecuária Brasileira 43: 281-284.

PEDRON FA et al. 2004. Parâmetros biométricos de fruto, endocarpo e semente de butiazeiro. Ciência Rural 34: 585586.

PEREIRAPC et al. 2008. Influência do tamanho de sementes na qualidade de mudas de tamarindeiro. Bioscience Journal 24: 73-79.

RITCHIE GA et al. 2010. Assessing plant quality. In: LANDIS TD et al. Seedling Processing, Storage and Outplanting. Washington: Department of Agriculture Forest Service. p. 17-81.

RESSEL $K$ et al. 2004. Ecologia morfofuncional de plântulas de espécies arbóreas da Estação Ecológica do Panga, Uberlândia, Minas Gerais. Revista Brasileira de Botânica 27: 311-323.

RODERJAN CV et al. 2002. As Unidades Fitogeográficas do Estado do Paraná, Brasil. Ciência \& Ambiente 24: 78118.

SANTOS FS et al. 2009. Biometria e qualidade fisiológica de sementes de diferentes matrizes de Tabebuia chrysotricha (Mart. Ex A. DC.) Standl. Scientia Forestalis 37:163-173.

SEO M et al. 2009. Interaction of light and hormone signals in germinating seeds. Plant Molecular Biology 69: 463472.

WIELEWICKI AP et al. 2006. Proposta de padrões de germinação e teor de água para sementes de algumas espécies florestais presentes na região sul do Brasil. Revista Brasileira de Sementes 28: 191-197. 